\title{
High trees increase sunflower seed predation by birds in an agricultural landscape of Israel
}

\author{
Jessica Schäckermann ${ }^{1,2 *}$, Noam Weiss ${ }^{3}$, Henrik von Wehrden ${ }^{4,5}$ and Alexandra-Maria Klein ${ }^{1,6}$ \\ 1 Ecosystem Functions, Institute of Ecology, Leuphana University Lüneburg, Lüneburg, Germany \\ ${ }^{2}$ Department of Entomology, The Robert H. Smith Faculty of Agriculture, Food and Environment, Hebrew University Rehovot, Israel \\ ${ }^{3}$ SPNI Society for Protection of Nature in Israel, Tel-Aviv, Israel \\ ${ }^{4}$ Centre of Methods and Institute of Ecology, Leuphana University Lüneburg, Lüneburg, Germany \\ ${ }^{5}$ Research Institute of Wildlife Ecology, University of Veterinary Medicine, Vienna, Austria \\ ${ }^{6}$ Nature Conservation and Landscape Ecology, Institute of Earth and Environmental Sciences, University of Freiburg, Freiburg, Germany
}

\section{Edited by:}

Eike Luedeling, World Agroforestry Centre, Kenya

\section{Reviewed by:}

Holger Hoffmann, Leibniz

Universität Hannover, Germany

Aidan M. Keith, Centre for Ecology

and Hydrology, UK

${ }^{*}$ Correspondence:

Jessica Schäckermann, Ecosystem

Functions, Institute of Ecology,

Leuphana University Lüneburg

Scharnhorststraße 1, 21335

Lüneburg, Germany

e-mail: jessica.schaeckermann@

leuphana.de
Natural habitats in agricultural landscapes promote agro-ecosystem services but little is known about negative effects (dis-services) derived by natural habitats such as crop seed predation. Birds are important seed predators and use high landscape structures to perch and hide. High trees in agricultural landscapes may therefore drive seed predation. We examined if the presence, the distance and the percentages of high trees (tree height $>5 \mathrm{~m}$ ) and the percentages of natural habitat surrounding sunflower fields, increased seed predation by birds in Israel. At the field scale, we assessed seed predation across a sample grid of an entire field. At the landscape scale, we assessed seed predation at the field margins and interiors of 20 sunflower fields. Seed predation was estimated as the percentage of removed seeds from sunflower heads. Distances of sample points to the closest high tree and percentage of natural habitat and of high trees in a $1 \mathrm{~km}$ radius surrounding the fields were measured. We found that seed predation increased with decreasing distance to the closest high tree at the field and landscape scale. At the landscape scale, the percentage of high trees and natural habitat did not increase seed predation. Seed predation in the fields increased by $37 \%$, with a maximum seed predation of $92 \%$, when a high tree was available within $0-50 \mathrm{~m}$ to the sunflower fields. If the closest high tree was further away, seed predation was less than $5 \%$. Sunflower seed predation by birds can be reduced, when avoiding sowing sunflowers within a radius of $50 \mathrm{~m}$ to high trees. Farmers should plan to grow crops, not sensitive to bird seed predation, closer to trees to eventually benefit from ecosystem services provided by birds, such as predation of pest insects, while avoiding these locations for growing crops sensitive to bird seed predation. Such management recommendations are directing toward sustainable agricultural landscapes.

Keywords: ecosystem dis-service, Israel, landscape ecology, landscape structures, natural habitat, vertebrate pests

\section{INTRODUCTION}

Insects provide valuable agro-ecosystem services and the interest in developing strategies to conserve beneficial insects, for example by integrating flower patches into agricultural areas, is growing (Bianchi et al., 2006; Carvalheiro et al., 2012; Blaauw and Isaacs, 2014). Besides the positive effects of natural and semi-natural habitats, these habitats might also promote organisms that influence crop production negatively, either directly by consuming parts or whole crop plants or indirectly by transmitting diseases (Dunn, 2010; Keesing et al., 2010; Blitzer et al., 2012). Insect pests are well known to negatively influence crop production (Oerke, 2005; Eilers and Klein, 2009; Cini et al., 2012; El-Wakeil and Volkmar, 2012) but seed or fruit predation by vertebrates can also lead to losses in crop growth and production (Moran and Keidar, 1993; Ahmad et al., 2011; De Mey et al., 2012). Research was carried out to identify the bird species involved and the extent of crop yield loss and possible control methods (Moran,
2003; Linz et al., 2011; Radtke and Dieter, 2011). Important bird pests for agricultural crops are for example the Canada Goose (Branta canadensis L.), the Chukar Partridge (Alectoris chukar Gray), the Rose-Ringed Parakeet (Psittacula krameri Scopoli), the Ring-Necked Phesant (Phasianus colchicus L.) and blackbirds (Icteridae) (Moran, 2003; Radtke and Dieter, 2011; Werner et al., 2011). Crops frequently and often heavily attacked by birds comprise almond (Emlen, 1937), sunflower, maize (Ahmad et al., 2011; Linz et al., 2011) and rice (De Mey et al., 2012). Until now, several methods have been tested to reduce seed predation by birds, which can be broadly divided into population suppression, frightening and evading (Linz et al., 2011). Population suppression methods such as culling or poisoning seem to be favored by farmers (Conover, 2002) but even though they may be effective they are also expensive (Malhi, 2005).

Subramanya (1994) found that flower height and head angle of sunflowers were correlated with seed predation by 
the Rose-Ringed Parakeet. Also Fleming et al. (2002) and Khaleghizadeh (2011) found, that the plant morphology is correlated to seed predation. Such studies are rare and information on the feeding behavior of main seed predators is crucial to advice management practices. Seed predation in sunflower fields, caused by foraging flocks of granivorous birds has been reported from India (Subramanya, 1994) and Pakistan (Ahmad et al., 2011) but occurs in fact in every major sunflower-growing regions of the world (Linz and Hanzel, 1997) (Table S1). Therefore, the sunflower crop system is a suitable model system to investigate the drivers of crop seed predation by birds. In general, the mechanisms leading to high abundance of seed-predating birds, including the surrounding landscape, have greatly been overlooked (Martin et al., 2013). In Israel, birds are well-known pests in sunflower farming (Moran, 2003; Nemtzov, 2003). Nemtzov (2003) described the Rose-Ringed Parakeet (Figure 1) as a pest in sunflower farming in Israel. In addition, the Hooded Crow (Corvus cornix L.) was found to be a pest in sunflower fields, while none of the other investigated vertebrate species, including rodents were found feeding on sunflower seeds (Moran, 2003). Other sunflower pests in the study area are the Eurasian Jay (Garrulus glandarius L.) (reported by local farmers), the Middle East Blind Mole Rat (Spalax ehrenbergi Nehring), which is known to feed on the roots of the sunflower plants, and a moth, the Cotton Bollworm (Helicoverpa armigera Hübner), with larvae developing in the flower heads, facilitating fungal infections (Heth, 1991).

Seed predation, in sunflower fields of Israel shows high spatial variance similar to observations made by Stone and Mott (1986), which found seed predation by the Red-Winged Blackbird, (Ageleaus phoeniceus L.), in some but not in all investigated maize fields. As seed predation is highly variable between fields, we assume that differences in the surrounding of the fields, like the proportion of natural and semi-natural habitat, buildings, tree cover and other habitat structures influence the magnitude of seed predation. Sheldon and Nadkarni (2013) found that isolated high trees are highly attractive habitat structures for birds in agricultural areas. Additionally Fischer et al. (2010) found that bird species richness in landscapes with trees

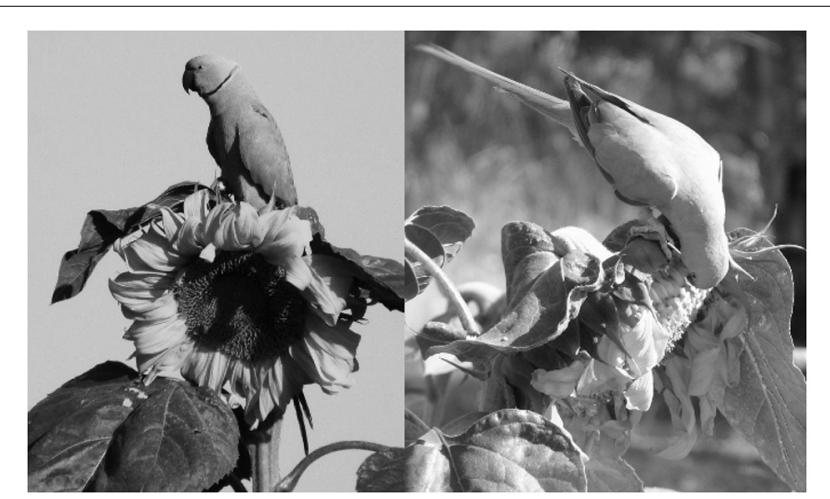

FIGURE 1 | Rose-Ringed Parakeets (Psittacula krameri Scopoli) resting on a sunflower and feeding on sunflower seeds in the field used for the field-scale data. was twice as high as in landscapes without trees. Many bird species use trees for observing, perching, foraging and roosting (Bull et al., 1992; Sonerud, 1992; Holl, 1998; Miller and Cale, 2000) and the presence of trees adjacent to crop fields may make the crops more accessible for the birds. Hence, we hypothesize that (1) habitat structures such as high trees in the surrounding of sunflower fields will increase seed predation by birds, since these structures upgrade the landscape for birds and make perching possible and foraging therefore easier; (2) seed predation increases with decreasing distance to the closest high tree (from now on termed high tree), due to reduced foraging and perching possibilities for birds; (3) the presence of high trees within a specific range influences seed predation by birds, because birds may only be able to use these trees for foraging and perching within a specific radius dependent on their visual capabilities; (4) seed predation increases with the percentage of tree cover but not with the percentage of natural habitat in the surrounding landscape, because high trees are not part of the natural habitat in our study area.

\section{MATERIALS AND METHODS STUDY AREA AND LANDSCAPE CHARACTERIZATION}

The study area is part of the Judean Foothills, approximately $30 \mathrm{~km}$ southwest of Jerusalem. The Judean Foothills are among the last remnants of a unique transient ecosystem at the interface of the humid Mediterranean ecosystem to its north and the arid ecosystem to its south (Weizel et al., 1978). The landscape is characterized by a mosaic of different land-use types; mainly natural habitats (scrublands of variable densities and stages of succession mainly lacking trees higher than $5 \mathrm{~m}$, with shrubs and herbs as main plant species), agricultural fields (annual and perennial crops), semi-natural habitats (planted forests comprising mainly pines of the species Pinus halepensis Miller, Pinus pinea L., Pinus brutia Tenore and to a lesser extent pines mixed with planted native broad-leave species), some rural settlements and a few urban and industrial areas (Weizel et al., 1978) (Figure 2).

\section{STUDY CROP SYSTEM: SUNFLOWER FIELDS}

The sunflower Helianthus annuus L. (Asteraceae) is an annual herb and in Israel grown for seed production but not for oil. Sowing takes place in March and harvest between July and September. Prior to our study, we interviewed local farmers to get information about pest species of the study area. The Rose-Ringed Parakeet was reported as being a severe pest species consuming seeds directly from sunflower heads (see also Nemtzov, 2003; Schäckermann and Weiss, personal observations, August 2010) (Figure 1).

We selected similarly managed sunflower fields, concerning time of sowing, irrigation and pesticide application, of three hybrid seed production varieties (Shelly, Shemesh, Dalet Yod 3). All fields were treated with the fungicide Bayfidan and with the insecticide Endosulfan once during bloom and irrigated with a drip system from April/May until June/July, depending on the time of sowing and harvesting. The sunflower fields were alternated with cotton, chickpea, watermelon, maize or spring 


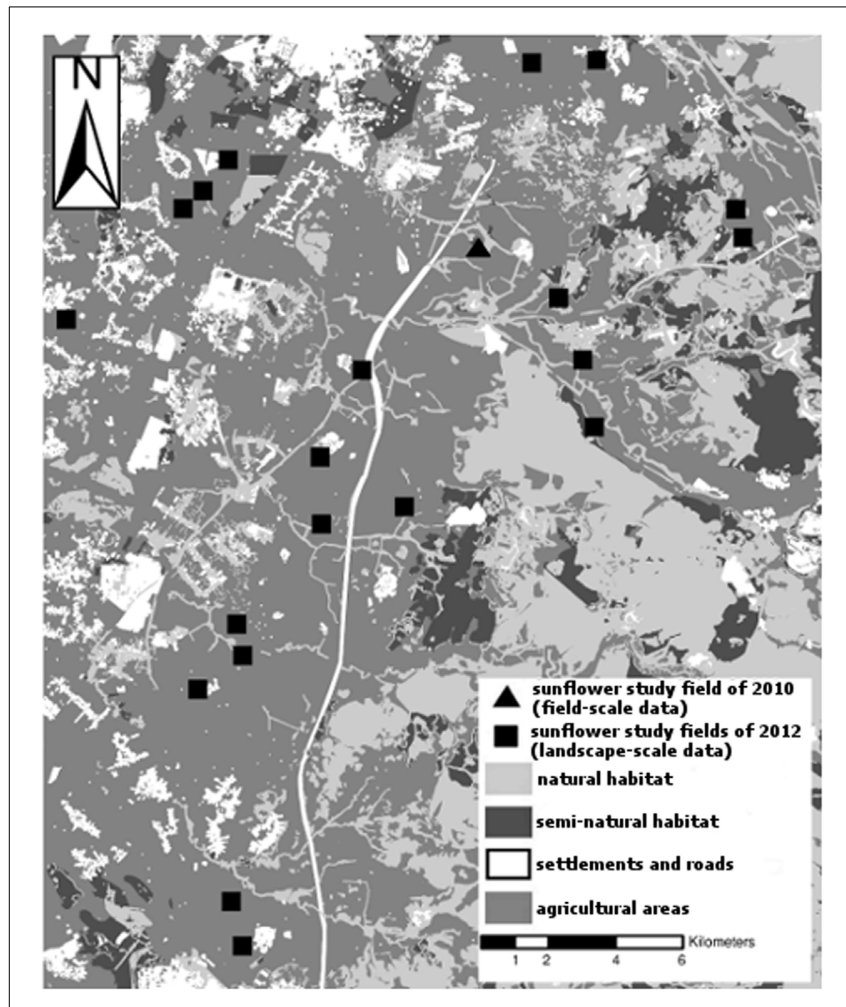

FIGURE 2 | Study area, habitat types and the distribution of the sunflower study fields at the field scale in $\mathbf{2 0 1 0}$ and at the landscape scale in 2012 in the Judean foothills of Israel.

wheat in the next season or with winter wheat in a doublecropping system in the same season. The size of fields varied from 1 to 66 ha.

\section{SUNFLOWER FIELD SELECTION}

One field with high visible seed predation was chosen in 2010 for field-scale data collection using a grid system. In this field at least half of the sunflower heads at the margins showed signs of seed predation and this was reported by sunflower farmers of the study area as highly predated by birds. Within the gridcollection system, vertical and horizontal rows were selected every $50 \mathrm{~m}$ for the entire field. At each of a total of 140 intercept points (when vertical and horizontal rows were crossing), we estimated the percentage of seed predation per each of 50 sunflower heads (summing up to a total of 7000 sunflower heads). The estimation of the percentage of seed predation is described in Estimating Seed Predation.

In 2012, we selected 20 sunflower fields for a landscape-scale data collection to re-assess our findings from 2010 on a larger scale and to integrate landscape variables. We chose 10 fields with visible seed predation at the margins (more than $50 \%$ of the heads showed $10-100 \%$ seed predation) and 10 fields with little or no visible seed predation at the field margins (more than $50 \%$ of the heads showed $0-5 \%$ seed predation). Margins were chosen for this assessment because in 2010 we found that they suffer most from seed predation. For each field we selected two sampling points: (1) at field margin and (2) the interior of the field. Minimum distance between margin sampling points of different fields was $1 \mathrm{~km}$. In each field, we used the margin with highest visible seed predation for sampling. In fields without or little seed predation we chose the margin sampling point randomly.

We measured the distances between the intercept points to the closest high tree (tree height $>5 \mathrm{~m}$, single tree or a group of trees with at least one tree taller than $5 \mathrm{~m}$ ) for all 140 intercept points of the field for the field-scale study in 2010 and for all margin and interior sampling points of all fields in 2012. We recorded the geographic coordinates at all margin sampling points of the fields in 2012 using GIS (ArcGIS, version 9.2., Esri 380 New York Street, Redlands, CA 92373-8100) and calculated in a $1 \mathrm{~km}$ radius surrounding the sampling point the (1) percentage of the natural habitat comprising scrubland without soil disturbance in the past 5 years $(0-33 \%)$, (2) percentage of tree cover comprising high trees (0-20\%), and (3) field size in ha. A $1 \mathrm{~km}$ radius is known to be an appropriate scale in vertebrate-focused landscape studies (Eilers and Klein, 2009; Guerrero et al., 2012). Land cover data was obtained from the archive of the Hebrew University.

\section{ESTIMATING SEED PREDATION}

We estimated sunflower seed predation of 50 randomly chosen sunflower heads at each of all 140 intercept points of the field in 2010; we therefore sampled 7000 sunflower heads in this one field. We furthermore sampled 50 randomly chosen sunflower heads each at the margin and interior sampling points in the 20 fields in 2012 (100 heads in each field and 2000 in total for 2012). We estimated seed predation per flower head by estimating the percentage of missing seeds caused by birds (seed predation estimated number of missing seeds eaten by birds/estimated number of all developed seeds in the head*100). Seeds were absent from sunflower heads through (1) seed predation by birds (Figure 1), (2) touching and rubbing of neighboring sunflower heads (mechanical removal), and (3) no development of seeds. Seeds removed by birds were distinguished from non-developed seeds because seeds removed after full development left "pockets" (palea adhered to the anthodium) (Figure 3) while these "pockets" were missing when unfertilized florets did not develop seeds. Mechanical removal was identified when complete seeds were found under the plant and this was not the case when seeds were eaten by birds.

\section{STATISTICAL ANALYSES}

We analyzed the field-scale count data from 2010 with generalized linear mixed models using a quasipoisson error distribution to account for over dispersion and penalized quasi likelihood (GLMM; packages = "nlme," "nlme4," “multcomp," “vegan”), (Script S2) (Pinheiro et al., 2007; Bates et al., 2013). We used generalized linear mixed models because of our non-normal distributed data (we did a visual test to find out if our data was normally distributed) and to fit in fixed factors as well as random factors. This approach is recommended in the literature (Bolker et al., 2009). Seed predation was used as response variable and distance from the sampling point to the closest high tree in meters as explanatory variable. For the landscape scale 


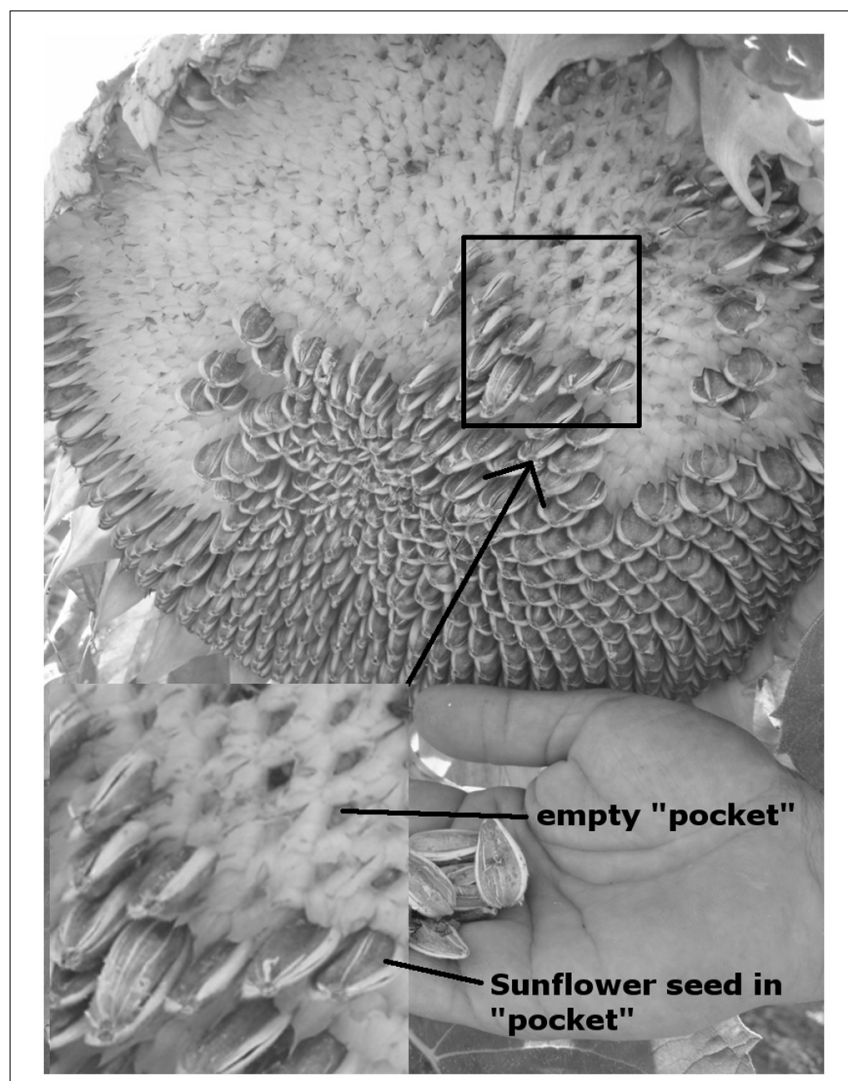

FIGURE 3 | Sunflower head with visible seed predation and empty sunflower shells from under the plant in the hand. Empty "pockets" of removed seeds and seeds in the "pockets" can be seen.

data comprising 20 fields in 2012, we also used generalized linear mixed models (Script S2). Models were analyzed using a poisson error distribution (to model the count data) or quasipoisson error distribution in case of over dispersion. Models with seed predation as response variable included the following explanatory variables as fixed factors: (1) distance from the sampling point to the closest high tree (in meters), (2) sampling point location (margin, interior), (3) percentage of tree cover in a $1 \mathrm{~km}$ radius surrounding the sampling point, (4) percentage of natural habitat in a $1 \mathrm{~km}$ radius surrounding the sampling point, (5) field size in ha. We used the additional explanatory variable (6) presence of high trees within $50 \mathrm{~m}$ for the landscape scale (tree or trees present (yes), no trees (no), because we detected similar patterns and a threshold of around $50 \mathrm{~m}$ at both the fieldscale and landscape-scale analyses (Figure 4), when testing the effect of distance to the closest high tree on seed predation. Field and location within the fields were included as random factors if they were not included as explanatory variable (e.g., Nelder and Wedderburn, 1972). Correlations between explanatory variables were tested with a correlation matrix based on Spearman (Table 1). Because some of the explanatory variables were correlated, all variables were tested in separate models. In the following we present the standard results given for mixed model summaries (Zuur et al., 2009). Amongst others we give $p$-values (P) of our models. The $p$-value can be defined as the probability (therefore has a value between zero and one) how likely it is to obtain such a sample result or a more extreme, if the null hypothesis is true. The threshold used was 5\% (0.05). Furthermore, we give the $t$-value (T) which measures how many standard errors the coefficient is away from zero. Generally, any $t$-value greater than +2 or less than -2 is acceptable. This is also the threshold we used for all our analyses. The higher the $t$-value, the greater the confidence we have in the coefficient as a predictor. Low $t$-values are indications of low reliability of the predictive power of that coefficient. All statistical analyses were conducted using $\mathrm{R}$ ( $\mathrm{R}$ Development Core Team, 2010, version 2.12.0).

\section{RESULTS}

Seed predation at the field scale in 2010 decreased with increasing distance to the closest high tree within $50 \mathrm{~m}$ ( $T=-2.8889$, $P=0.0045$ ) (Figure 4A). At the landscape scale in 2012, seed predation within the field margins was higher than in the interiors of the fields (Table 2), therefore margins and interiors were evaluated separately. Similar to the findings at the field scale, seed predation at the margin sampling point of sunflower fields decreased with increasing distance to the closest high tree (Figure 4B, Table 2), showing the same threshold of $50 \mathrm{~m}$ like the field-scale data (Figures 4A,B). When testing the effect of the $50 \mathrm{~m}$ threshold at the landscape scale, seed predation at the margin sampling point of sunflower fields was higher in fields surrounded by high trees within $50 \mathrm{~m}$ than in fields without high trees in this radius (Figure 5, Table 2). At the margins, we found an average seed predation rate of $37 \%$, with a maximum of up to $92 \%$ if high trees were present within $50 \mathrm{~m}$. Less than $5 \%$ seed predation was observed at field margins if the closest high tree was further than $50 \mathrm{~m}$ away. While seed predation at the margins decreased with increasing distance to the closest high tree, it was not related to the overall percentage of tree cover in the surrounding landscape (Table 2). When considering the field interior sampling point only, seed predation was not related to the distance of the closest high tree (Table 2). Seed predation by birds at both sampling points was neither related to the percentage of natural habitat surrounding the fields nor to the field size (Table 2).

\section{DISCUSSION \\ HIGH TREES ADJACENT TO CROP FIELDS AND SEED PREDATION}

Seed predation increased strongly with decreasing distance to the closest high tree or tree group within $50 \mathrm{~m}$ in our study. Because birds were the main sunflower seed predators in our study area, our results agree with the findings of Hanspach et al. (2011) who found that scattered trees were key habitat structures for birds in semi-natural open areas. We observed flocks of a few hundreds of birds of the Rose-Ringed Parakeet in our study area, (Personal Observation and reports by local farmers) (Figure 1), one of the main bird pests to agriculture in Israel (Nemtzov, 2003). However, in other agricultural areas in Israel, flocks with up to a few thousands of birds were reported by local farmers (Personal Communication, Yoav Motro, Ministry of Agriculture and Environment).

In areas with higher bird abundance, the pressure on individual birds to locate food should be stronger, and they may therefore 

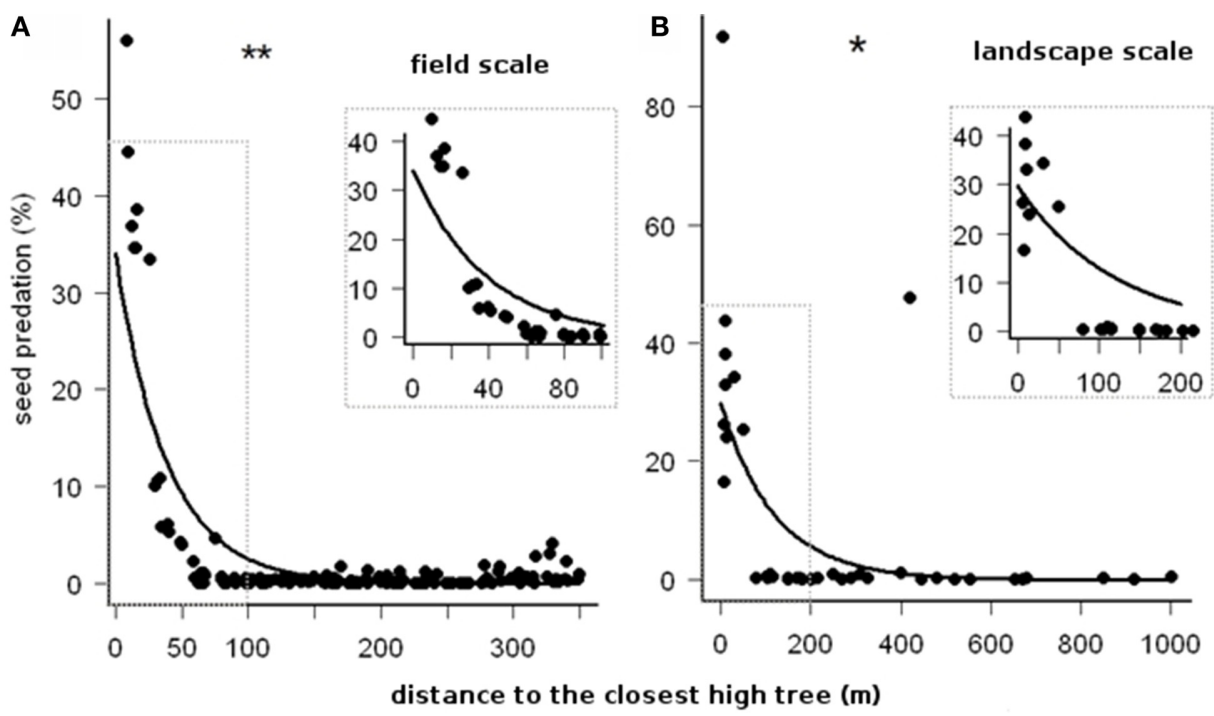

FIGURE 4 | Percentage of seed predation per field and intercept/ sampling point (shown as mean seed predation per sampling point) in relation to the distance of closest high tree, (A) of the entire field sampled in $\mathbf{2 0 1 0}$ and in the inset, intercept points that were not further than $\mathbf{1 0 0} \mathbf{m}$ from the next high tree for statistics see Results.

(B) Across all fields sampled in 2012, and in the inset only the sampling points with a high tree within $200 \mathrm{~m}(T=-2.5025, P=0.0216) .{ }^{*} p<0.05$; ** $p<0.005$

Table 1 | Correlation matrix of the explanatory variables field size in ha, presence of high trees (higher than $5 \mathrm{~m}$ ) within $50 \mathrm{~m}$ to the sampling points (at least a single tree or a group of trees was present within $50 \mathrm{~m}$ to the sampling point), distance to the closest high tree (single or group) in $\mathbf{m}$ from the sampling point, natural habitat in \% surrounding the sampling point in a $\mathbf{1} \mathbf{k m}$ radius and tree cover in $\%$ surrounding the sampling point in a $1 \mathrm{~km}$ radius) was used to analyze correlations between explanatory variables.

Field size

(ha)

-
0.0259
-0.1594
0.054
0.1038

\section{Presence of high} trees (within $50 \mathrm{~m}$ )

\section{Distance to high}

tree $(\mathrm{m})$
Natural habitat

(\%)

0.5021
0.0002
-
-0.0773
-0.4972

0.8213

0.5105

0.7461

0.8213
0.5105
0.7461
-
0.5074

0.7468

0.1563

$-0.3797$

$-0.4972$

0.5074
Tree cover

(\%)

Correlation coefficients are given on white background, p-values on light gray background. For more information see Statistical Analyses.

Table 2 | Effects on the percentage of seed predation of sunflower at the landscape scale in relation to the sampling point, presence of high trees (higher than $5 \mathrm{~m}$ ) within $\mathbf{5 0} \mathrm{m}$ to the sampling points, distance to the closest high tree or tree groups, natural habitat in \% surrounding the sampling point in a $\mathbf{1} \mathbf{k m}$ radius, tree cover in \% surrounding the sampling point in a $\mathbf{1} \mathbf{k m}$ radius and field size in ha.

\begin{tabular}{|c|c|c|c|c|c|c|}
\hline Explanatory Variables & Sampling point & Estimate & Std. Error & $D F$ & $t$-value & $p$-value \\
\hline Presence of high trees $(50 \mathrm{~m})$ & Margin & -4.4583 & 0.6759 & 18 & -6.5959 & $<0.0001$ \\
\hline Distance to high tree $(\mathrm{m})$ & Interior & -0.0013 & 0.0011 & 18 & -1.1486 & 0.2658 \\
\hline Distance to high tree $(\mathrm{m})$ & Margin + Interior & -0.0017 & 0.0046 & 19 & -0.3735 & 0.7129 \\
\hline Natural habitat (\%) & Margin & -0.0630 & 0.0728 & 18 & -0.8652 & 0.3983 \\
\hline Field size (ha) & Margin & -0.0234 & 0.0388 & 18 & -0.6025 & 0.5544 \\
\hline
\end{tabular}

Significant relationships are highlighted in bold (Std. Error is the standard Error; DF stands for Degrees of Freedom). Data was analyzed with generalized linear mixed models. For more information concerning the statistical analysis see Statistical Analyses. 


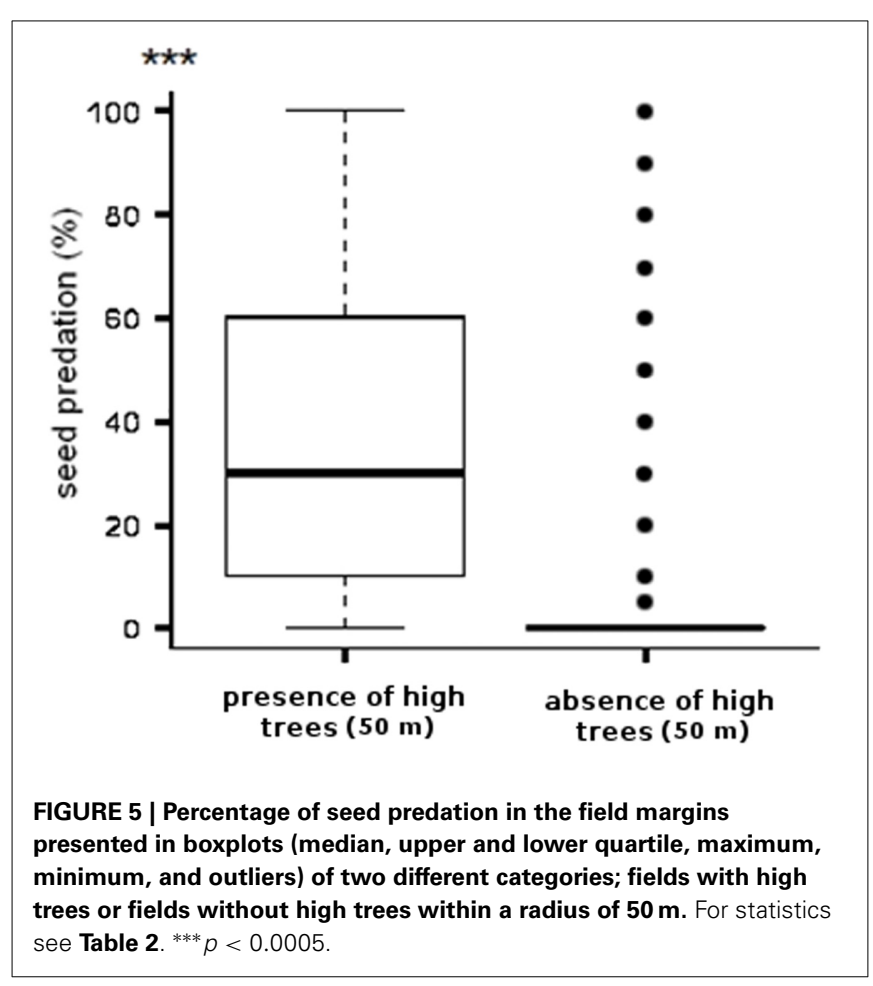

exceed the main foraging distance of $50 \mathrm{~m}$ we found in our study. When comparing seed predation at the margin sampling points to the interior sampling points of the field- and at the landscape scale, we found that the margins were more affected, showing that birds live outside the sunflower fields and gradually forage toward the interior, starting at the margins. Many species tend to feed on field margins and may only move to the field interiors when food resources become limited (Kollmann and Buschor, 2002). This was also supported by our results for seed predation at the field scale throughout an entire field. Here, we found the highest seed predation at the margin intercept points of the field adjacent to a high tree or small group of trees. Hence, a field that seems highly predated at the margin does not necessarily show predation in the interior. High trees or tree groups are usually located outside the fields and therefore sunflower plants in the interior are generally further away than plants at the margin.

The dependence of seed-predating birds on high trees may also explain the high spatial variance in seed predation between different fields. If there were no high trees adjacent to the fields, we only observed very little seed predation, but there was a dramatic increase in crop seed predation by birds in crops adjacent to high trees. While birds seemed to depend on the presence of high trees to scope parts of the landscape as potential feeding areas, a higher percentage of tree cover did not cause higher seed predation in crop fields. Therefore, the high spatial variance in seed predation seems to be related to the appearance of high trees used for perching by birds. This supports findings of Fischer et al. (2010) where the number of trees was rather negligible and only the general presence of a single tree drove the overall pattern of bird richness in an Australian livestock grazing landscape. Therefore, individual trees should be taken into account in land-management planning, since at least in Israel it is not an easy option to cut trees in agricultural areas, because permissions for doing so are needed for every tree. We furthermore observed Hooded Crows picking single sunflower seeds and consume them outside of the crop fields, while the RoseRinged Parakeet consumed many seeds without moving at top of the sunflower heads in the fields (Schäckermann, personal observations and see also Figure 1). Even though the crow and the parakeet are both granivorous birds and crows have a higher body mass, their actual contribution to seed predation may vary considerably mediated by their predation activity. Therefore, different granivorous bird taxa should be considered (Notman et al., 1996). Hence, feeding behavior as well as local abundances of main bird species found in agricultural areas, that can influence the high spatial variance in seed predation between different fields, should be taken into account when predicting the impact of birds on seed predation. Even though high trees were the main perch (high structures for birds to sit on and perch) in our study, we also observed high seed predation by birds in one field with no trees in its surroundings (outlier in Figure 5). However, we did find electric pylons and power lines next to the field and small buildings in the area. Therefore, the availability of perches may influence seed predation in sunflowers. Future research should therefore investigate the impact of these manmade landscape structures (alone and in combination with high trees) and different habits of different seed predators. This may lead to more detailed management recommendations regarding the interaction effects of different natural and man-made landscape structures on biodiversity and ecosystem services or dis-services relationships.

\section{NATURAL HABITAT AND SEED PREDATION BY AN INVASIVE BIRD}

Natural habitats can cause services (benefits) or dis-services (negative effects) or a combination of both to agriculture (Zhang et al., 2007; Bommarco et al., 2013; Martin et al., 2013; Ango et al., 2014). In our study, natural habitats were found to be unsuitable for sunflower seed-predating birds because they did not contain trees that could be used as perching structures. Also other studies found that natural and semi-natural field margins are not suitable as breeding habitats for birds feeding on crops, but offered shelter to a broad range of bird species (for example Song Sparrow Melospiza melodia Wilson, Vesper Sparrow Pooecetes gramineus Gmelin, Savannah Sparrow Passerculus sandwichensis Gmelin, Red-winged Blackbird Agelaius phoeniceus L. and American Goldfinch Carduelis tristis L.) potentially useful for biological pest control (Jobin et al., 2001). High natural trees rarely occur in our study area in Israel, but introduced highgrown Eucalyptus trees can be frequently found. In our study area, high Eucalyptus trees are often located close to settlements, probably grown to spend shade in summer (Schäckermann, personal observations). Because it is known that many bird species prefer high landscape structures for perching (Bull et al., 1992; Sonerud, 1992; Holl, 1998; Miller and Cale, 2000), the presence of trees taller than $5 \mathrm{~m}$ improves the habitat quality, especially for birds originated in forest areas, like the RoseRinged Parakeet, one of the main seed predators on sunflower in Israel. Furthermore, Rose-Ringed Parakeets depend on cavities 
as nesting sites (Strubbe and Matthysen, 2007). In our study area, Rose-Ringed Parakeets used holes in buildings as nesting places (Weiss, personal observation) and crops they used as food resources are often planted close to settlements. Knowing that the Rose-Ringed Parakeet, which is an invasive bird in Israel and an agricultural pest, uses an introduced tree species for perching indicates, that humans can unintentionally create suitable habitats for pest bird species. Ornithologists and nature conservationists in Israel are concerned that the high numbers of Parakeets negatively influence the population density of native cavity-nesting birds, by occupying their nesting sites and reducing their breeding success (Weiss, communication with local conservationists and ornithologists). Birds of concern are the Hoopoe (Upupa epops L.), Syrian Woodpecker (Dendrocopos syriacus Hemprich and Ehrenberg) and European Scops Owl (Otus scops L.). Research about the effects of the introduced Rose-Ringed Parakeet on native cavity-nesting bird species and other invasive birds showed, that there are complex interactions between invasive birds, these interactions had an effect on native cavity-nesting birds (Orchan et al., 2013) showing, that a complex interaction network between native and invasive bird species exists. Globally invasive species have enormous ecological and economic costs and are an important threat to biodiversity (Wilson, 1992; Pimentel et al., 2005; Shine et al., 2009). There are many hypotheses on why birds established and/or are becoming invasive (e.g., Case, 1996; Blackburn and Duncan, 2001; Duncan et al., 2003; Cassey et al., 2004; Blackburn et al., 2009). Nevertheless, more knowledge is needed about the impact of invasive bird species on the environment and economy in the invaded range.

\section{CONCLUSIONS, RECOMMENDED MANAGEMENT PRACTICES AND FUTURE RESEARCH}

To minimize the negative impact of birds to crop harvest, a shift in management practices considering landscape structures such as high trees seems necessary and habitat management is recommended to potentially control populations of birds acting as agricultural pests (MacLeod et al., 2011). Our results show that farmers should avoid growing crops, which are susceptible to seed predation by birds, adjacent to high trees (tree height $>5 \mathrm{~m}$ ) and if possible decide to grow crops which are not likely to suffer from seed predation by birds closer to high trees. Crops that are susceptible to bird seed predation should not be adjacent to high trees, to reduce seed predation. The location and shape of fields should therefore be planned according to surrounding conditions.

Also bird population suppression methods like culling or poisoning, which are used by agricultural producers (Conover, 2002), could be replaced by advanced crop planning, taking into account high trees and other natural and man-made landscape structures that can be used as perches. Distances of these structures to the fields should be taken into account, to include spanned distances between fields and target bird species in the planning. Hence future research should aim to understand the habitat requirements of bird pests and their foraging behavior, since effective management and conservation of avian communities require our understanding of temporal patterns of bird abundance and their implications (Best, 2001). This will help finding solutions to reduce crop seed predation harming agriculture and the environment. By spreading our results across farmers, high-quality habitats for bird pests adjacent to agricultural fields susceptible to bird seed predation can be reduced with the long-term conservation goal to control or even reduce the populations of bird pests. Since natural pest control concerns not only single fields but whole agricultural landscapes, farmers in the same region need to work jointly to implicate landscape management to promote ecosystem services while reducing ecosystem dis-services.

\section{ACKNOWLEDGMENTS}

The present work was financed by a research grant (11-76-25199-06/08) of the Ministry for Science and Culture of Lower Saxony. Jessica Schäckermann was supported by the German Academic Exchange Program (DAAD). We thank Gideon Pisanty and Ariella Gotlieb for help in the field and Yoav Motro, for information on sunflower cultivation practices, pests and pesticides. We thank Jean Gaffney for language corrections and Yael Mandelik as well as Gesine Pufal for helpful comments on the manuscript. We are especially grateful to the participating farmers for access to their fields and orchards.

\section{SUPPLEMENTARY MATERIAL}

The Supplementary Material for this article can be found online at: http://www.frontiersin.org/journal/10.3389/fevo.2014.00035/ abstract

\section{REFERENCES}

Ahmad, S., Khan, H., and Javed, M. (2011). Roost composition and damage assessment of rose-ringed parakeet (psittacula krameri) on maize and sunflower in agro-ecosystem of central punjab, pakistan. Int. J. Agric. Biol. 13, 731-736.

Ango, T. G., Börjeson, L., Senbeta, F., and Hylander, K. (2014). Balancing ecosystem services and disservices: smallholder farmers' use and management of forest and trees in an agricultural landscape in southwestern ethiopia. Ecol. Soc. 19:30. doi: 10.5751/ES-06279-190130

Bates, D., Maechler, M., Bolker, B., and Walker, S. (2013). lme4: Linear Mixed-Effects Models Using Eigen and S4. R package version, 1.

Best, L. B. (2001). Temporal patterns of bird abundance in cornfield edges during the breeding season. Am. Midl. Nat. 146, 94-104. doi: 10.1674/00030031(2001)146[0094:TPOBAI]2.0.CO;2

Bianchi, F., Booij, C. J., and Tscharntke, T. (2006). Sustainable pest regulation in agricultural landscapes: a review on landscape composition, biodiversity and natural pest control. Proc. R. Soc. B. 273, 1715-1727. doi: 10.1098/rspb.2006.3530

Blaauw, B. R., and Isaacs, R. (2014). Flower plantings increase wild bee abundance and the pollination services provided to a pollination-dependent crop. J. Appl. Ecol. doi: 10.1111/1365-2664.12257. [Epub ahead of print].

Blackburn, T. M., Cassey, P., and Lockwood, J. L. (2009). The role of species traits in the establishment success of exotic birds. Glob. Chang. Biol. 15, 2852-2860. doi: 10.1111/j.1365-2486.2008.01841.x

Blackburn, T. M., and Duncan, R. P. (2001). Determinants of establishment success in introduced birds. Nature 414, 195-197. doi: 10.1038/35102557

Blitzer, E. J., Dormann, C. F., Holzschuh, A., Klein, A.-M., Rand, T. A., and Tscharntke, T. (2012). Spillover of functionally important organisms between managed and natural habitats. Agric. Ecosyst. Environ. 146, 34-43. doi: 10.1016/j.agee.2011.09.005

Bolker, B. M., Brooks, M. E., Clark, C. J., Geange, S. W., Poulsen, J. R., Stevens, M. H. H., et al. (2009). Generalized linear mixed models: a practical guide for ecology and evolution. Trends Ecol. Evol. 24, 127-135. doi: 10.1016/j.tree.2008.10.008 
Bommarco, R., Kleijn, D., and Potts, S. G. (2013). Ecological intensification: harnessing ecosystem services for food security. Trends Ecol. Evol. 28, 230-238. doi: 10.1016/j.tree.2012.10.012

Bull, E. L., Holthausen, R. S., and Henjum, M. G. (1992). Roost trees used by pileated woodpeckers in northeastern oregon. J. Wildl. Manage. 56, 786-793.

Carvalheiro, L. G., Seymour, C. L., Nicolson, S. W., and Veldtman, R. (2012). Creating patches of native flowers facilitates crop pollination in large agricultural fields: mango as a case study. J. Appl. Ecol. 49, 1373-1383. doi: 10.1111/j.1365-2664.2012.02217.x

Case, T. J. (1996). Global patterns in the establishment and distribution of exotic birds. Biol. Conserv. 78, 69-96. doi: 10.1016/0006-3207(96)00019-5

Cassey, P., Blackburn, T. M., Sol, D., Duncan, R. P., and Lockwood, J. L. (2004). Global patterns of introduction effort and establishment success in birds. Biol. Lett. 271, 405-408. doi: 10.1098/rsbl.2004.0199

Cini, A., Ioriatti, C., and Anfora, G. (2012). A review of the invasion of drosophila suzukii in europe and a draft research agenda for integrated pest management. Bull. Insectol. 65, 149-160.

Conover, M. R. (2002). Resolving Human-Wildlife Conflicts: The Science of Wildlife Damage Management. Boca Raton, FL: CRC Press.

De Mey, Y., Demont, M., and Diagne, M. (2012). Estimating bird damage to rice in africa: evidence from the senegal river valley. J. Agric. Econ. 63, 175-200. doi: 10.1111/j.1477-9552.2011.00323.x

Duncan, R. P., Blackburn, T. M., and Sol, D. (2003). The ecology of bird introductions. Annu. Rev. Ecol. Evol. S. 34, 71-98. doi: 10.1146/132353

Dunn, R. (2010). Global mapping of ecosystem disservices: the unspoken reality that nature sometimes kills us. Biotropica 42, 555-557. doi: 10.1098/rspb.2010.0340.F

Eilers, E., and Klein, A. (2009). Landscape context and management effects on an important insect pest and its natural enemies in almond. Biol. Control 51, 388-394. doi: 10.1016/j.biocontrol.2009.07.010

El-Wakeil, N. E., and Volkmar, C. (2012). Effect of jasmonic application on economically insect pests and yeald in spring wheat. Gesunde Pflanz. 64, 107-116. doi: 10.1007/s10343-012-0278-x

Emlen, J. T. (1937). Bird damage to almonds in california. Condor 39, 192-197. doi: $10.2307 / 1363803$

Fischer, J., Stott, J., and Law, B. S. (2010). The disproportionate value of scattered trees. Biol. Conserv. 143, 1564-1567. doi: 10.1016/j.biocon.2010. 03.030

Fleming, P. J., Gilmour, A., and Thompson, J. A. (2002). Chronology and spatial distribution of cockatoo damage to two sunflower hybrids in south-eastern australia, and the influence of plant morphology on damage. Agric. Ecosyst. Environ. 91, 127-137. doi: 10.1016/S0167-8809(01)00241-9

Guerrero, I., Morales, M., Oñate, J., Geiger, F., Berendse, F., Snoo, G., et al. (2012) Response of ground-nesting farmland birds to agricultural intensification across europe: landscape and field level management factors. Biol. Conserv. 152, 74-80. doi: 10.1016/j.biocon.2012.04.001

Hanspach, J., Fischer, J., Stott, J., and Stagoll, K. (2011). Conservation management of eastern australian farmland birds in relation to landscape gradients. J. Appl. Ecol. 48, 523-531. doi: 10.1111/j.1365-2664.2010.01948.x

Heth, G. (1991). The environmental impact of subterranean mole rats (Spalax ehrenbergi) and their burrows. Sym. Zool. S. 63, 265-280.

Holl, K. (1998). Do bird perching structures elevate seed rain and seedling establishment in abandoned tropical pasture? Restor. Ecol. 6, 253-261. doi: 10.1046/j.1526-100X.1998.00638.x

Jobin, B., Choinière, L., and Bélanger, L. (2001). Bird use of three types of field margins in relation to intensive agriculture in québec, canada. Agric. Ecosyst. Environ. 84, 131-143. doi: 10.1016/S0167-8809(00)00206-1

Keesing, F., Belden, L. K., Daszak, P., Dobson, A., Harvell, C. D., Holt, R. D., et al. (2010). Impacts of biodiversity on the emergence and transmission of infectious diseases. Nature 468, 647-652. doi: 10.1038/nature09575

Khaleghizadeh, A. (2011). Effect of morphological traits of plant, head and seed of sunflower hybrids on house sparrow damage rate. Crop Prot. 30, 360-367. doi: 10.1016/j.cropro.2010.12.023

Kollmann, J., and Buschor, M. (2002). Edges effects on seed predation by rodents in deciduous forests of northern switzerland. Plant Ecol. 164, 249-261. doi: 10.1023/A:1021225728493

Linz, G. M., and Hanzel, J. J. (1997). "Birds and sunflower in," in Sunflower Technology and Production, ed A. A. Schneiter (American Society of Agronomy,
Crop Science Society of America, and Soil Science Society of America. Agronomy Monograph no. 35), 381-394.

Linz, G. M., Homan, H. J., Werner, S. J., Hagy, H. M., and Bleier, W. J. (2011). Assessment of bird-management strategies to protect sunflowers. Bioscience 61, 960-970. doi: 10.1525/bio.2011.61.12.6

MacLeod, C. J., Tompkins, D. M., Drew, K. W., and Pyke, N. (2011). Does farmscale habitat composition predict pest-bird numbers and distribution? Wildl. Res. 38, 464. doi: 10.1071/WR11045

Malhi, C. S. (2005). Comparative efficacy of different methods of management for preventing bird damage in sunflower crop. Int. Pest Control 47, 16-17.

Martin, E. A., Reineking, B., Seo, B., and Steffan-Dewenter, I. (2013). Natural enemy interactions constrain pest control in complex agricultural landscapes. Proc. Natl. Acad. Sci. U.S.A. 110, 5534-5539. doi: 10.1073/pnas. 1215725110

Miller, J., and Cale, P. (2000). Behavioral mechanisms and habitat use by birds in a fragmented agricultural landscape. Ecol. Appl. 10, 1732-1748. doi: 10.1890/1051-0761(2000)010[1732:BMAHUB]2.0.CO;2

Moran, S. (2003). Checklist of vertebrate damage to agriculture in israel, updated for 1993-2001. Phytoparasitica 31, 109-117. doi: 10.1007/BF02980779

Moran, S., and Keidar, H. (1993). Checklist of vertebrate damage to agriculture in israel. Crop Prot. 12, 173-182. doi: 10.1016/0261-2194(93)90105-R

Nelder, J. A., and Wedderburn, R. W. M. (1972). Generalized linear models. J. R. Stat. Soc. Ser. A-G. 135, 370-384. doi: 10.1002/0471667196.ess0866.pub2

Nemtzov, S. (2003). Preventing Agricultural Damages. Israel: Israel National Park Authority Report.

Notman, E., Gorchov, D. L., and Cornejo, F. (1996). Effect of distance, aggregation, and habitat on levels of seed predation for two mammal? Dispersed neotropical rain forest tree species. Oecologia 106, 221-227. doi: 10.1007/ BF00328602

Oerke, E. C. (2005). Crop losses to pests. J. Agric. Sci. 144, 31-43. doi: 10.1017/S0021859605005708

Orchan, Y., Chiron, F., Shwartz, A., and Kark, S. (2013). The complex interaction network among multiple invasive bird species in a cavity-nesting community. Biol. Invasions 15, 429-445. doi: 10.1007/s10530-012-0298-6

Pimentel, D., Zuniga, R., and Morrison, D. (2005). Update on the environmental and economic costs associated with alien-invasive species in the united states. Ecol. Econ. 52, 273-288. doi: 10.1016/j.ecolecon.2004. 10.002

Pinheiro, J., Bates, D., DebRoy, S., and Sarkar, D. (2007). Linear and Nonlinear Mixed Effects Models. R package version, 3, 57.

R Development Core Team. (2010). R: A Language and Environment for Statistical Computing. Vienna: R Foundation for Statistical Computing. Available online at: http://www.R-project.org/

Radtke, T., and Dieter, C. (2011). Canada goose crop damage abatement in south dakota. Hum. Wildl. Interact 5, 315-320.

Sheldon, K. S., and Nadkarni, N. M. (2013). The use of pasture trees by birds in a tropical montane landscape in monteverde, costa rica. J. Trop. Ecol. 29, 459-462. doi: 10.1017/S0266467413000503

Shine, C., Kettunen, M., Ten Brink, P., Genovesi, P., and Gollasch, S. (2009). "Technical support to EU strategy on invasive species (IAS)," in Recommendations on Policy Options to Control the Negative Impacts of IAS on Biodiversity in Europe and the EU, Final Report for the European Commission (Brussels: Institute for European Environmental Policy (IEEP)), 35.

Sonerud, G. (1992). Search tactics of a pause-travel predator: adaptive adjustments of perching times and move distances by hawk owls (Surnia ulula). Behav. Ecol. Sociobiol. 30, 207-217. doi: 10.1007/BF00166705

Strubbe, D., and Matthysen, E. (2007). Invasive ring-necked parakeets psittacula krameri in belgium: habitat selection and impact on native birds. Ecography (Cop.) 30, 578-588. doi: 10.1111/j.2007.0906-7590.05096.x

Stone, C. P., and Mott, D. F. (1986). Bird Damage to Ripening Field Corn in the United States, 1971. US Department of the Interior, Fish and Wildlife Service, Bureau of Sport Fisheries and Wildlife.

Subramanya, S. (1994). Non-random foraging in certain bird pests of field crops. J. Biosci. 19, 369-380. doi: 10.1007/BF02703174

Weizel, Y., Polak, G., and Cohen, Y. (1978). Ecology of the Vegetation in Israel. Petach-Tikva: The Ecology Branch.

Werner, S. J., Linz, G. M., Carlson, J. C., Pettit, S. E., Tupper, S. K., and Santer, M. M. (2011). Anthraquinone-based bird repellent for sunflower 
crops. Appl. Anim. Behav. Sci. 129, 162-169. doi: 10.1016/j.applanim.2010. 11.010

Wilson, E. O. (1992). The Diversity of Life. Cambridge, MA: Belknap.

Zhang, W., Ricketts, T., and Kremen, C. (2007). Ecosystem services and dis-services to agriculture. Ecol. Econ. 64, 253-260. doi: 10.1016/j.ecolecon.2007.02.024

Zuur, A., Ieno, E. N., Walker, N., Saveliev, A. A., and Smith, G. M. (2009). Mixed Effects Models and Extensions in Ecology with R. Springer. Available online at: http://www.google.co.il/books?hl=en\&lr=\&id=vQUNprFZKHsC\&pgis $=1$

Conflict of Interest Statement: The authors declare that the research was conducted in the absence of any commercial or financial relationships that could be construed as a potential conflict of interest.
Received: 01 May 2014; accepted: 23 June 2014; published online: 16 July 2014. Citation: Schäckermann J, Weiss N, von Wehrden H and Klein A-M (2014) High trees increase sunflower seed predation by birds in an agricultural landscape of Israel. Front. Ecol. Evol. 2:35. doi: 10.3389/fevo.2014.00035

This article was submitted to Agroecology and Land Use Systems, a section of the journal Frontiers in Ecology and Evolution.

Copyright (c) 2014 Schäckermann, Weiss, von Wehrden and Klein. This is an openaccess article distributed under the terms of the Creative Commons Attribution License (CC BY). The use, distribution or reproduction in other forums is permitted, provided the original author(s) or licensor are credited and that the original publication in this journal is cited, in accordance with accepted academic practice. No use, distribution or reproduction is permitted which does not comply with these terms. 